\title{
Bilateral pulmonary embolism as initial presentation of invasive adenocarcinoma of the colon
}

\author{
Gabriel Cecenas Salas ${ }^{1}$, Lauren Burgess ${ }^{1}$ and Smita Subramaniam ${ }^{2 *}$ \\ ${ }^{1}$ University of North Texas Health Science Center, Texas College of Osteopathic Medicine, Fort Worth, TX, USA \\ ${ }^{2}$ Teaching Attending in Internal Medicine, John Peter Smith Health Network, Associate Professor, University of North Texas Health Science Center, Fort Worth, \\ TX, USA
}

\begin{abstract}
Venous thromboembolism due to acquired hypercoagulable state in cancer patients is a well-known phenomenon. It is a frequent cause of death in this patient population. Prompt diagnosis and adequate management is needed for these patients to have favorable outcomes. In our patient with severe anemia, diagnosis with pulmonary embolism and subsequent diagnosis of colon cancer highlights the importance of systematic workup and management until a definite diagnosis is obtained.
\end{abstract}

\section{Introduction}

Venous thromboembolism (VTE) is a common and frequently encountered diagnosis in the hospital setting. It is estimated that 1 to 2 per 1000 people in America are diagnosed with this affliction every year [1]. There are numerous risk factors for thromboembolism, both genetic and acquired. Acquired risk factors include surgery, malignancy, congestive heart failure, estrogen therapy, smoking, immobilization, trauma and autoimmune disorders. Common inherited causes include antithrombin 3 deficiency, protein $\mathrm{C}$ and $\mathrm{S}$ deficiency, factor 5 Leiden mutation, factor 20210 prothrombin mutation, and hyperhomocysteinemia [2]. VTE is one of the most common causes of death in cancer patients [3], with overall prognosis being worse if cancer and thromboembolic event are diagnosed in quick succession of one another [4]. We present an interesting case of a patient presenting with severe anemia and dyspnea, a common scenario which led to the diagnosis of bilateral pulmonary embolism and subsequently adenocarcinoma colon.

\section{Case}

A 43-year-old male presented to the hospital with midsternal chest pain, dyspnea and diaphoresis along with a syncopal episode. He had been experiencing lightheadedness, fatigue and dyspnea on exertion for 1 week prior to his admission. He has a history of hypertension and remote hip surgery, but no significant family history or allergies. He also denied taking medications or supplements, smoking or substance abuse.

Initial examination showed afebrile patient with respiratory rate of 35 per minute, pulse at 119 per minute, blood pressure of 132/86 and oxygen saturations of $94 \%$ on room air. Physical examination showed normal head and neck exam, clear lungs and no abnormality in cardiac or abdominal exam. There was no pedal edema.

Initial labs revealed hemoglobin of $6.9 \mathrm{~g} / \mathrm{dL}$, mean corpuscular volume of 58, white count was 12.6 and platelets were 560,000 . Chemistry showed creatinine at 1.3, BNP was 2,285 (reference less than $125 \mathrm{pg} / \mathrm{ml}$ ), INR of 1.3 and negative toxicology screen. EKG showed sinus tachycardia with incomplete right bundle branch block and chest $\mathrm{x}$-ray was normal. He also got CTA of the chest which showed multiple acute pulmonary emboli in bilateral main pulmonary arteries (Figure 1). Fecal occult blood was positive although patient denied any melena, hematochezia or hematemesis. Because patient was not acutely bleeding and was hemodynamically stable, decision was made to start IV heparin as benefits outweighed the risks. The patient also received 2 units PRBC transfusion. Stat echocardiogram was obtained which showed right ventricular strain and reduced right-sided systolic function, consistent with cardiovascular compromise caused by the magnitude of patient's clot burden. Due consideration was given for possible catheter directed thrombolysis by Interventional Radiology but was not done due to patient's severe anemia and patient being hemodynamically stable.
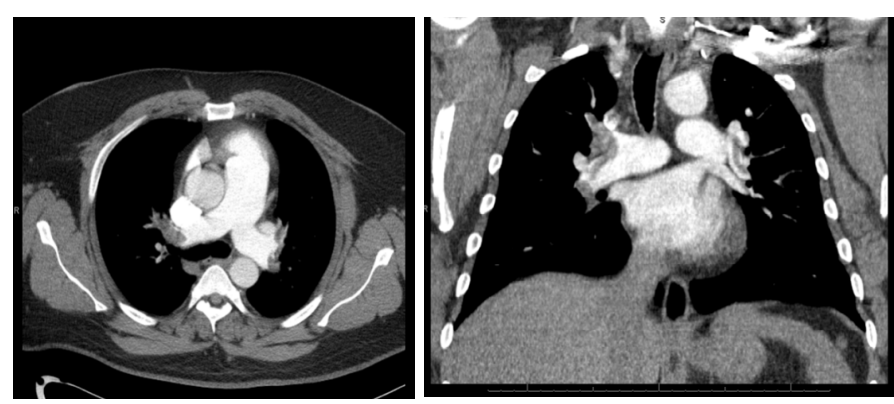

Figure 1. Axial and Coronal sections of chest computed tomography (CT) Angiogram showing filling defects to bilateral proximal pulmonary arteries consistent with bilateral submassive pulmonary emboli

${ }^{*}$ Correspondence to: Smita Subramaniam, MD, FACP, John Peter Smith Health Network, 1500 S Main St, Fort Worth, TX 76104, USA, Tel: 8177023431; E-mail: SSubrama@jpshealth.org

Key words: pulmonary embolism, adenocarcinoma colon, iron deficiency anemia, hypercoagulable states

Received: October 17, 2018; Accepted: October 31, 2018; Published: November 05, 2018 
Doppler ultrasound of the lower extremities was negative for DVT. Workup was also done for ruling out hypercoagulable state due to mutations and it was negative. CT scan of abdomen and pelvis showed a mass in the ascending colon (Figure 2) and CT head was negative. Patient underwent colonoscopy which confirmed the presence of a greater than $5 \mathrm{~cm}$ partially obstructing friable and ulcerated mass in the ascending colon (Figure 3). Surgery was consulted for right-sided hemicolectomy and decision was taken to perform the surgery in a few weeks after anticoagulation due to the significant clot burden. Patient was transitioned to oral Apixaban before discharge and was given proper appointments for follow-up.

\section{Discussion}

Thrombosis is a common complication of malignancy and represents the second most frequent cause of death-about $13 \%$ in cancer patients receiving chemotherapy in an ambulatory setting, commonest cause being progression of disease in $70 \%$ of cases [3]. Active cancer accounts for almost $20 \%$ of new VTE events due to hypercoagulability; and although the majority of pulmonary emboli originate from deep vein thrombosis of the lower extremity, that is not always the case $[5,6]$.

The highest incidence of VTE is found in mucin producing carcinomas of the pancreas and gastrointestinal tract, lung and ovarian cancer [5]. Among gastrointestinal malignancies, gastric carcinoma generally has much higher incidence of VTE compared to colon cancer. In one study, patients with metastatic colorectal cancer had an incidence rate of approximately $4.3 \%$ [7]. Although the cumulative incidence of pulmonary embolism in patients with colon cancer is not as high as
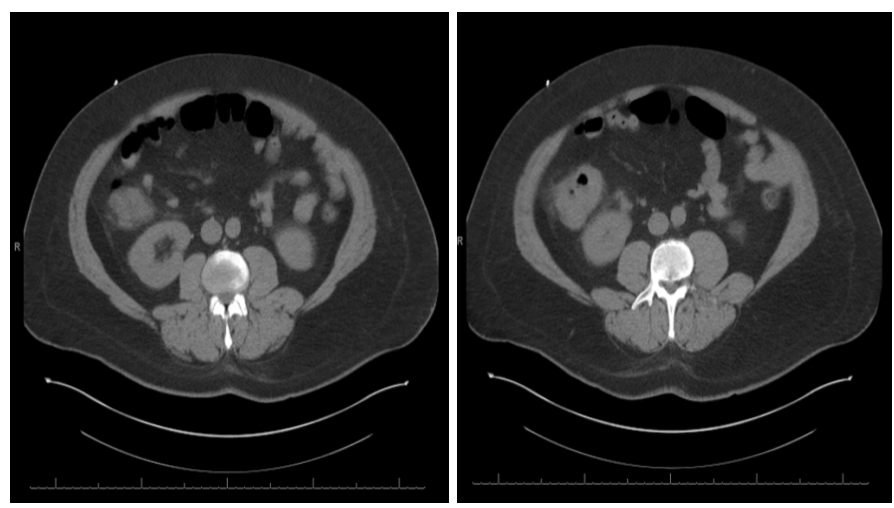

Figure 2. Axial sections of abdomen computed tomography (CT) showing Prominent soft tissue mass involving the ascending colon and cecum at and above the level of the ileocecal junction compatible with locally invasive malignant colonic neoplasm
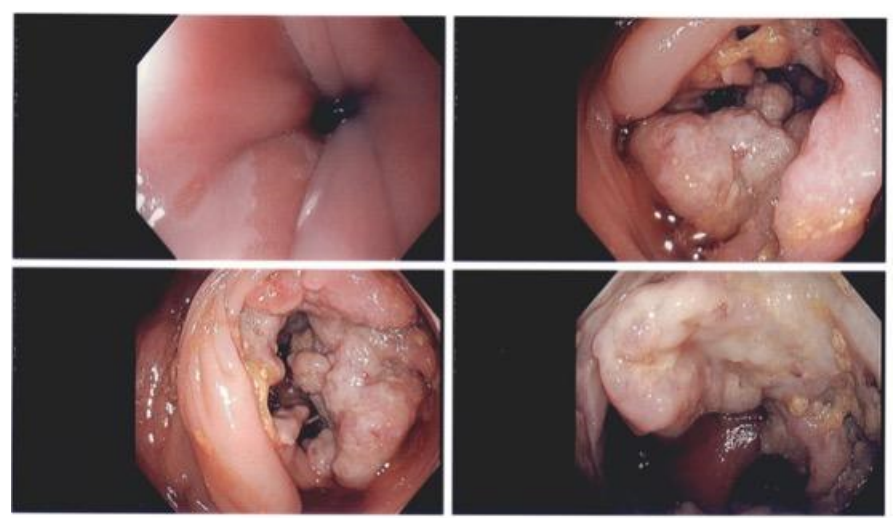

Figure 3. Representative images from colonoscopy showing large ulcerated circumferential, friable, partially obstructing right sided colonic mass spanning $5 \mathrm{~cm}$ in many other malignancies $[5,8]$, VTE may reflect the presence of biologically more aggressive cancer and is a significant predictor of death within one year of diagnosis [5,7].

Cancer patients treated with anticoagulation have lower mortality rates. Although the American Society of Clinical Oncology guidelines recommend treatment with low molecular weight heparin (LMWH) for cancer associated thromboembolism $[8,9]$, new evidence suggests that direct oral anticoagulants (DOACs) may be reasonable alternatives to LMWH [9]. For our patient, it was decided to give apixaban for long term anticoagulation due to the ease of use and overall lower cost for the patient. The recent approval of antidote to dabigatran, rivaroxaban and apixaban is increasing the confidence of physicians regarding safe use of DOACs for patients needing anticoagulation.

The unique aspects of this case like severe anemia and risk of bleeding with the need for anticoagulation raise the awareness of varied and co-existing disorders that can significantly impact the diagnosis and treatment of cancer patients

\section{The takeaway}

Systematic and continued workup is required for common presentations, like severe anemia with dyspnea, to arrive at the final diagnosis. This will ensure appropriate and timely management of lifethreatening disease processes, which in our patient included bilateral pulmonary embolism as well as adenocarcinoma of colon.

\section{References}

1. Beckman MG, Hooper WC, Critchley SE, Ortel TL (2010) Venous thromboembolism: a public health concern. Am J Prev Med 38: S495-501. [Crossref]

2. Dalen JE (2002) Pulmonary embolism: What have we learned since Virchow? Natural history, pathophysiology, and diagnosis. Chest 122: 1440-1456. [Crossref]

3. Khorana AA, Francis CW, Culakova E, Kuderer NM, Lyman GH (2007) Thromboembolism is a leading cause of death in cancer patients receiving outpatient chemotherapy. J Thromb Haemost 5: 632-634. [Crossref]

4. Sørensen HT, Mellemkjaer L, Olsen JH, Baron JA (2000) Prognosis of cancers associated with venous thromboembolism. $N$ Engl J Med 343: 1846-1850. [Crossref]

5. Caine GJ, Stonelake PS, Lip GY, Kehoe ST (2002) The hypercoagulable state of malignancy: pathogenesis and current debate. Neoplasia 4: 465-473. [Crossref]

6. Lee JS, Moon T, Kim TH, Kim SY, Choi JY, et al. (2016) Deep vein thrombosis in patients with pulmonary embolism: prevalance, clinical significance and outcome. Vasc Specialist Int 32: 166-174. [Crossref]

7. Alcalay A, Wun T, Khatri V, Chew HK, Harvey D, et al. (2006) Venous thromboembolism in patients with colorectal cancer: incidence and effect on survival. J Clin Oncol 24: 1112-1118. [Crossref]

8. Wun T, White RH(2009) Epidemiology of cancer-related venous thromboembolism. Best Pract Res Clin Haematol 22: 9-23. [Crossref]

9. Raskob GE, van Es N, Verhamme P, Carrier M, Di Nisio M, et al. (2018) Edoxaban for the treatment of cancer-associated venous thromboembolism. N Engl J Med 378: 615-624. [Crossref]

Copyright: (C2018 Salas GC. This is an open-access article distributed under the terms of the Creative Commons Attribution License, which permits unrestricted use, distribution, and reproduction in any medium, provided the original author and source are credited. 